\title{
Vacuum Preconsolidation Settlement Characteristics and Microstructural Evolution of Marine Dredger-Filled Silt
}

\author{
Keping Chen, ${ }^{1,2}$ Xinkai Ren, ${ }^{1,2}$ Yong He $\mathbb{D}^{1,2}$ Muyuan Gan, ${ }^{3}$ Danwei Wu, ${ }^{3}$ \\ and Lianwei Chen ${ }^{3}$ \\ ${ }^{1}$ Key Laboratory of Metallogenic Prediction of Nonferrous Metals and Geological Environment Monitoring \\ (Central South University), Ministry of Education, Changsha, China \\ ${ }^{2}$ School of Geosciences and Info-Physics, Central South University, Changsha 410083, China \\ ${ }^{3}$ Guangxi Liuzhou Iron and Steel Group Company Limited, Liuzhou 545002, China
}

Correspondence should be addressed to Yong He; heyong18@csu.edu.cn

Received 25 February 2021; Accepted 16 June 2021; Published 22 June 2021

Academic Editor: Peng Zhang

Copyright ( 2021 Keping Chen et al. This is an open access article distributed under the Creative Commons Attribution License, which permits unrestricted use, distribution, and reproduction in any medium, provided the original work is properly cited.

\begin{abstract}
The method of vacuum preloading for foundation treatments is used in the construction of the Fangchenggang coastal area in Guangxi province, China. The thick marine dredger-filled silt has a considerable impact on the treatment effort. In this study, the mineral composition and grain size distribution of these silts were analyzed to investigate their consolidation settlement property and microstructures. The scanning electron microscope and finite element method were adopted. The results reveal that the dredger-filled silt in this area is composed mainly of sand with particle size mostly smaller than $0.075 \mathrm{~mm}$. To replicate the construction process, the process of drainage by the vacuum preloading method was simulated by setting different water levels in the finite element analysis. The displacement and the dissipation of the pore water pressure obtained by simulations were reasonably consistent with the field monitoring data. In addition, the results obtained using the scanning electron microscope indicate that the equivalent diameter of the structural unit and that of the pore unit decrease with the silt depth. However, the value of the structural abundance approaches one, whereas the pore abundance is significantly different from one.
\end{abstract}

\section{Introduction}

To increase the area of coastal and lakeside construction lands, the method of land reclamation with dredger-filled soil is adopted to treat the foundation [1]. After the treatment, the foundation is composed of dredger-filled sands, dredger-filled silt, or a mixture of the two [2]. Its composition is exceptionally nonuniform, and the engineering performance is low [3-7]. In foundation treatment, vacuum preloading with simple construction and low cost is generally used to reinforce hydraulic fill foundation [8]. It is necessary to study the vacuum preloading consolidation settlement characteristics and microstructures of dredgerfilled silt to satisfy the requirements for constructing buildings on foundations. It is also important to establish a dredger-filled silt consolidation model to provide a theoretical basis for long-term postconsolidation settlement.

Extensive comparative investigations have been carried out on the formation process and macroscopic consolidation settlement characteristics or microscopic composition structure of dredger fills worldwide. In the initial studies on soft soil deformation, scholars observed that the results of large deformations of soft soils calculated using the classical Terzaghi theory were inconsistent with in situ results. Subsequently, the Barron consolidation theory was put forward and widely used [9]. It is more suitable than the Terzaghi consolidation theory for analyzing the consolidation and settlement of foundation after plastic drainage board treatment [10]. For example, Rujikiatkamjorn and Indraratna [11] presented a procedure for designing vertical 
drains on soft soils. They provided examples considering the linear variation in the horizontal permeability coefficient. The equivalent diameter equation was proposed according to different geotechnical conditions. Among these, the most widely used are equivalent area and equivalent perimeter $[12,13]$. Sun et al. obtained [14] finite element calculation results using the Biot consolidation theory and Duncan-Zhang nonlinear constitutive model. These show that the law of vacuum degree along depth is consistent with the scenario of on-site construction. Huang et al. [15] proposed the elliptic cylindrical coordinate theory for the consolidation of sand drain foundations and obtained a new fundamental consolidation equation. It demonstrated that the drainage effect of plastic drainage panels cannot be satisfied when the equivalent perimeter method is applied.

To speed up the consolidation process of soft soils and increase the strength, scholars have combined other ground treatment methods to address hydraulic fill soft soil foundations on the basis of plastic drainage boards. The vacuumsurcharge preloading method was proposed and has been demonstrated to be effective for increasing foundation strength and the degree of consolidation (e.g., $[16,17])$. Liu et al. [18] improved the vacuum preloading method and developed a new method for alternate vacuum preloading. Through the mercury intrusion test and shear test, Liu verified that the direction of movement of the dredger fill particles can be altered with this method and that the dissipation rate of pore water pressure is five times that of the traditional method. Scholars also adopted plastic drainage boards in combination with other foundation treatments such as deep mixing piles [19] and cement-soil piles [20] to treat soft soils. The treatment method can reduce the surface settlement as well as the lateral displacement of foundation.

Scholars have conducted various analyses on dredger fill using modern scientific and technological means, to address its micromechanism. Manning et al. and Spearman et al. $[21,22]$ studied the deposition patterns of clay and sandy soil mixtures in European estuaries and explained the interaction between sand and mud during sedimentation. Zhang et al. [23] simulated the consolidation process of dredger fill in a laboratory. They observed that the degree of agglomeration of particles in the deep part was higher than that in the shallow part. Furthermore, the degree of agglomeration of particles in the shallow part varied more than that in the vertical direction. The vertical and horizontal variations for different depths were similar. Zhang et al. and Liu et al. $[23,24]$ simulated the formation process of dredger fill. They observed the variation in dredger fill particles in the vertical and horizontal directions and divided the sedimentation of dredger fill into two stages: fine particle flocculation sedimentation and mud self-weight consolidation. Some researchers explored the relationship between the deposition of soft soil and the $\mathrm{pH}$ of the sedimentary environment [25-27]. They summarized the law of the effect of $\mathrm{pH}$ on the physical properties of soft soil, such as porosity and compressibility. Meanwhile, a series of shear tests were conducted on structured and unstructured clay to study their stress-strain laws [28-30]. Cheng et al. [31] divided the shear process into three stages using scanning electron microscope analysis: pore gas compression and water migration, agglomerate spallation and particle slip, and structure destruction and formation of new structures.

Research on the vacuum preloading consolidation settlement performance of dredger-filled silt can not only avoid the serious consequences of foundation instability, foundation damage, and even cracking of upper buildings but also provide construction basis for building structures or further foundation treatment. In the present study, the consolidation characteristics and micromechanism of the dredger-filled silt were studied from both the macro- and microperspectives through mineral analysis, pore microstructure analysis, consolidation test, and finite element simulation. This would provide a theoretical basis for subsequent ground treatment and postsurcharge.

\section{Materials and Methods}

2.1. Materials. Marine dredger-filled silt was sampled from different depths by in situ drilling from the coastal area formed by dredging and reclaiming land in Fangchenggang, Guangxi province, China (Figure 1). The silt soil layer in this coastal area would be treated with the vacuum preloading method in the future.

The physical and mechanical properties of the dredgerfilled silt at various depths are shown in Table 1 . The fact that the liquidity indexes (the most important parameters) of the samples from the different depths are higher than one indicates that the marine dredger-filled silt is in a fluid plastic state. Meanwhile, this type of silt has rich water content and high porosity: its natural water content is higher than the liquid limit, and its void ratio is higher than 1.5.

2.2. Experimental Method. To explore the micromechanism of the process of consolidation, the microstructure of marine dredger-filled silt was explored on the basis of three aspects: mineral composition, particle analysis, and scanning electron microscope analysis. In the X-ray diffraction (XRD) method, diffraction occurs when X-rays are directed into the crystal lattice of clay minerals. Different clay minerals have different lattice structures, whereby different diffraction patterns would be produced. The mineral composition can be determined by analyzing the diffraction patterns. The particle analysis methods that are applied differ with the grain size. A sieving test was used for large-size particles to determine the percentage of each particle group in the total mass of soil particles in the marine dredger-filled silt. Meanwhile, laser particle size analysis was used for smallsize particles. Herein, the size of soil particles is determined according to the principle of light scattering.

A scanning electron microscope (SEM) was used to observe the pore size, and the shape, composition, and connection of the marine dredger-filed silt particles. Furthermore, the interaction between different particles was analyzed using electron microscopy images.

Soil consolidation is a process of compression settlement in which air and water are discharged gradually from the soil under a certain pressure. The oedometer test is the most 


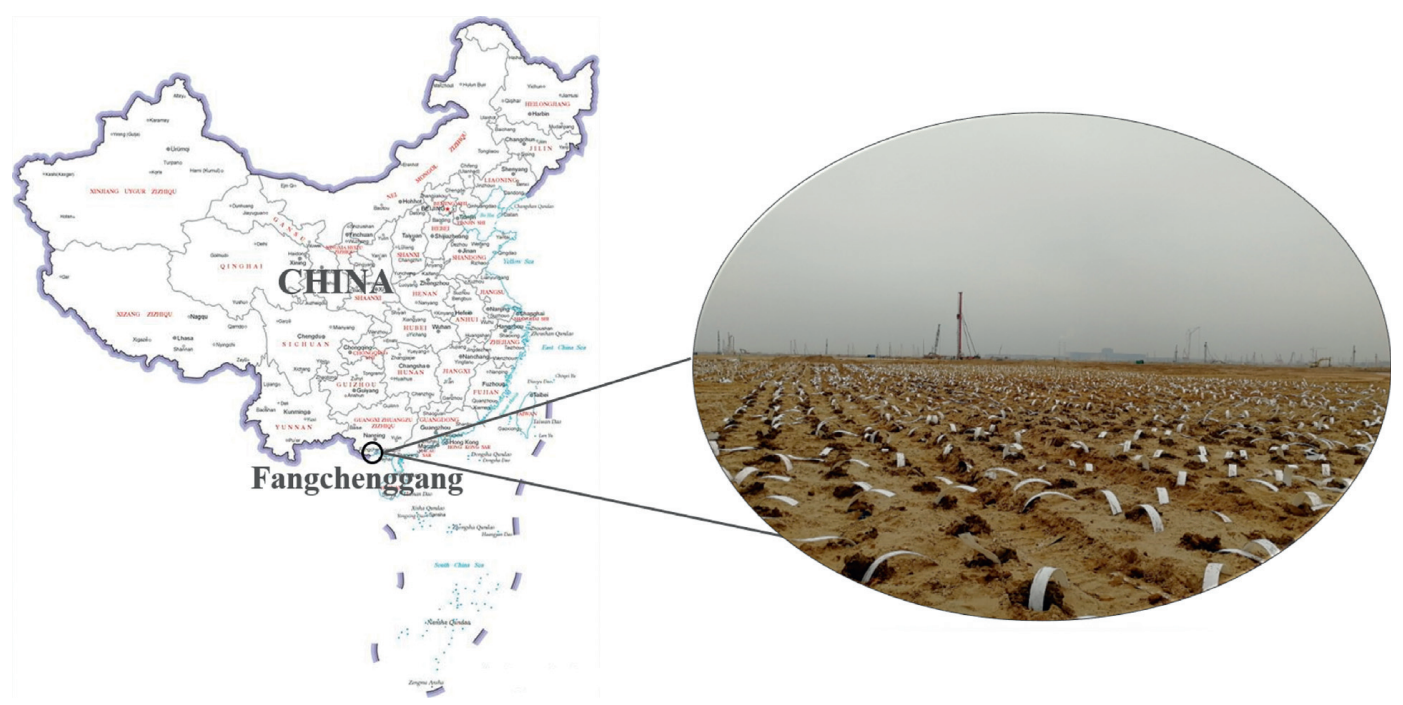

FIGURE 1: The sampled geographic location.

TABLE 1: Physical and mechanical properties of the dredger-filled silt at different depths.

\begin{tabular}{|c|c|c|c|c|c|c|c|c|}
\hline $\begin{array}{l}\text { Depth } \\
(\mathrm{m})\end{array}$ & $\begin{array}{l}\text { Density } \\
\left(\mathrm{g} / \mathrm{cm}^{3}\right)\end{array}$ & $\begin{array}{c}\text { Water } \\
\text { content }(\%)\end{array}$ & $\begin{array}{l}\text { Specific } \\
\text { gravity }\end{array}$ & $\begin{array}{c}\text { Plasticity } \\
\text { index }\end{array}$ & $\begin{array}{c}\text { Liquidity } \\
\text { index }\end{array}$ & $\begin{array}{c}\text { Compression factor } \\
\mathrm{a}_{1-2}\left(\mathrm{MPa}^{-1}\right)\end{array}$ & $\begin{array}{c}\text { Permeability } \\
\text { coefficient }(\mathrm{cm} / \mathrm{s})\end{array}$ & $\begin{array}{l}\text { Void } \\
\text { ratio } \\
\end{array}$ \\
\hline 1 & 1.673 & 62.6 & 2.687 & 22.255 & 1.833 & 1.446 & $3.07 E-07$ & 1.611 \\
\hline 3 & 1.692 & 62.3 & 2.630 & 26.954 & 1.468 & 1.152 & $3.20 E-06$ & 1.568 \\
\hline 6 & 1.719 & 65.1 & 2.674 & 26.700 & 1.582 & 1.311 & $1.75 E-06$ & 1.523 \\
\hline
\end{tabular}

common method to measure the consolidation and compression characteristics of soil. The compression deformation of marine dredger-filled silt at different depths under different pressure states $(1.0,12.5,25.0,50.0,100.0,200.0$, and $400.0 \mathrm{kPa}$ ) was tested using this method. Then, the relationship of consolidation pressure with silt deformation and void ratio was analyzed. Furthermore, the consolidation and compression deformation characteristics of marine dredger-filled silt were studied.

\subsection{Numerical Simulation}

2.3.1. Sand Well Equivalent. Owing to the small size of the plastic drainage plate, it is inconvenient to divide the mesh for finite element calculation. Therefore, in the present study, the sand well equivalent method was adopted to transform the sand well foundation into a sand wall foundation [32].

The smearing effect of the plastic drainage board in the laying process is considered. Furthermore, the average consolidation degree of the foundation can be ensured to be equal before and after mean time according to the sand well equivalent method mentioned above. The equivalent formula is as follows:

$$
\begin{aligned}
& k_{x p}=D_{x} \times k_{r a}, \\
& k_{z p}=D_{z} \times k_{z a},
\end{aligned}
$$

where $k_{x p}$ and $k_{z p}$ are the horizontal and vertical permeability coefficients, respectively, of the sand wall foundation; $k_{r a}$, and $k_{z a}$ are the radial and axial permeability coefficients, respectively, of the sand well foundation; and $D_{x}$ and $D_{z}$ are the adjustment coefficients of the horizontal and vertical permeability coefficients, respectively, and are expressed as follows:

$$
\begin{aligned}
& D_{x}=\frac{4\left(n_{p}-s_{p}\right)^{2}(1+v)^{2}}{9 n_{p}^{2} \mu_{a}-12 \beta\left(n_{p}-s_{p}\right)\left(s_{p}-1\right)(1+v) L^{2}}, \\
& D_{z}=\frac{2(1+v)}{3},
\end{aligned}
$$

$\mu_{a}$ represents the affecting coefficient of smear area and is expressed as follows:

$$
\begin{aligned}
\mu_{a} & =\frac{n^{2}}{n^{2}-s^{2}} \ln \frac{n}{s}-\frac{3 n^{2}-s^{2}}{4 n^{2}}+\frac{k_{r a}}{k_{s}} \frac{n^{2}-s^{2}}{n^{2}} \ln s ; \\
L & =\frac{B}{r_{e}} ; \\
\beta & =\frac{k_{r a}}{k_{s}},
\end{aligned}
$$

where $B$ is half of the sand wall spacing in the sand wall foundation; $r_{e}$ is the effective drainage radius of the sand well foundation; $n$ is the diameter ratio of the sand well in the sand well foundation, $n=r_{e} / r_{w a}$; $s$ is the ratio of the smear radius to the sand well radius in the sand well foundation, $s=r_{s} / r_{w a} ; n_{p}$ is the ratio of $B$ to half of the sand wall thickness, $n_{p}=B / r_{w p} ; s_{p}$ is the ratio of half the thickness of the sand wall 
to half the thickness of the sand wall, $s_{p}=r_{s p} / r_{w p} ; k_{s}$ is the permeability coefficient of sand well; and $v$ is Poisson's ratio of the foundation soil.

The dredger fill foundation of Fangchenggang is vacuum-preloaded with plastic drainage boards. These are laid in square with a spacing of $0.9 \mathrm{~m}$. This configuration is equivalent to a sand wall foundation according to the above formulas, with $r_{w a}=r_{w p}=0.033 \mathrm{~m}, B=2 \mathrm{~m}$, and $r_{e}=0.508 \mathrm{~m}$. Considering the influence of the drainage board coating on the consolidation degree [33], $s=s_{p}=3$ is adopted. The equivalent results are shown in Table 2.

2.3.2. Modeling and Parameters. After transforming the three-dimensional sand well foundation into a two-dimensional sand wall foundation, the conditions and stages of construction are set according to the on-site scenario of vacuum preloading. In addition, the finite element analysis is established according to the physical and mechanical parameters of the soil in the construction field. The parameters are shown in Table 3.

The vacuum preloading model $(54(\mathrm{~L}) \times 20.6(\mathrm{~W}) \mathrm{m})$ established by MIDAS GTS is shown in Figure 2. The model was divided into 4418 meshes with width of $0.5 \mathrm{~m}$ and length of $0.5 \mathrm{~m}$. From the top to the bottom, it is cohesive fill $(1.6 \mathrm{~m}$ in thickness), dredger-filled silt (7.8 $\mathrm{m}$ in thickness), silty sand $(1.2 \mathrm{~m}$ in thickness), and strongly differentiated sandstone (10 $\mathrm{m}$ in thickness). Sand walls are arranged at a distance of $2 \mathrm{~m}$ in the middle of the model, and a row of clay sealing walls with a width of $1.2 \mathrm{~m}$ is set on both sides of the sand wall foundation.

The foundation surface and sand wells between the two rows of sealed walls are set as drainage boundaries to simulate the on-site drainage conditions. Because sand wells are equivalent to plastic drainage boards without consolidation, the sand wells are set as nonconsolidated conditions. The negative pressure of vacuum is simulated by setting the node head. At the site, the negative pressure of vacuum is applied step by step and stabilized at $-85 \mathrm{kPa}$. Therefore, the foundation surface nodes and sand well nodes between the two rows of sealing walls are set to a pore water pressure of $-8.5 \mathrm{~m}$, and the foundation surface nodes outside the two rows of sealing walls are set to zero pore water pressure. The on-site pore water pressure monitoring data reveals that the on-site water level has decreased by $6 \mathrm{~m}$. Hence, the groundwater level has decreased from $19 \mathrm{~m}$ to $13 \mathrm{~m}$ over six times.

2.3.3. Assumptions. To explore the consolidation settlement characteristics of marine dredger-filled silt, the sand well foundation was converted into a sand wall foundation to simulate the on-site vacuum preloading. The assumptions are as follows:

(1) The plastic drainage board is regarded as a sand well according to the equivalent area, and the smearing effect of the plastic drainage board in the laying process is considered. The smearing radius is three times that of the sand well.
(2) The conversion between the sand well foundation and sand wall foundation is equivalently obtained based on Biot's axisymmetric consolidation theory. This can ensure that the degree of consolidation in the sand well foundation and sand wall foundation is identical and that the average pore pressure at each depth remains constant over time.

(3) The node water head on the sand wall is $-8.5 \mathrm{~m}$. In addition, the surface of the foundation is set according to the scenario of the on-site vacuum preloading, where the stable negative pressure is $-85 \mathrm{kPa}$. The water level decreases continuously in the process of on-site foundation consolidation. Therefore, the finite element analysis adopts multiple precipitations in layers to simulate the decrease in water level.

\section{Results and Discussion}

3.1. Characterization of the Soils. The microstructure of soil is composed of minerals, and the mineral content affects the physical and mechanical properties of soil. The crystalline structure and mineral composition of the soil were analyzed by XRD. As illustrated in Figure 3, the mineral composition mainly constitutes quartz, mica, and kaolinite. This indicates that the marine dredger-filled silt contains a large amount of sand and is plastic in this area.

To explore the particle size distribution of marine dredger-filled silt, the particle size of the soil sample was analyzed using the method and the laser grain size analyzer. These effectively demonstrated the grain size distribution of the marine dredger-filled silt, as shown in Figure 4.

Figure 4 shows that the main range of the grain size of the marine dredging silt is below $0.75 \mathrm{~mm}$, which accounts for $90.5 \%$ of the total particle content. This indicates that the field dredger-filled silt can be classified as fine-grained soil. The content of particles smaller than $0.075 \mathrm{~mm}$ is $99 \%$ and that of clay particles smaller than $0.005 \mathrm{~mm}$ is $30.8 \%$. This indicates that the marine dredger-filled silt particles are mainly powder particles, followed by clay particles.

Figure 5 shows the microstructure of the marine dredging silt after magnification by 20,000 times using the scanning electron microscope. It shows the relatively large pores of the marine dredger-filled silt, long flocculent soil particles, disordered particles, and significantly loose structure.

3.2. Oedometer Test Results. Figure 6 shows the relationship of the consolidation pressure with the void ratio and axial strain, obtained through the oedometer test of the dredgerfilled silt at depths of $1 \mathrm{~m}, 3 \mathrm{~m}$, and $6 \mathrm{~m}$.

The relationship between the void ratio of dredger-filled silt and consolidation pressure is shown in Figure 6(a). The void ratio of dredger-filled silt at the same depth decreases gradually with the increase in consolidation pressure. Essentially, the void ratio is directly proportional to the logarithm of consolidation pressure. Under constant consolidation pressure, the pore ratio of dredger-filled silt 
TABle 2: Parameters of sand wall foundation.

\begin{tabular}{lccccccccc}
\hline Soil classification & $r_{w p}(\mathrm{~m})$ & $r_{s p}(\mathrm{~m})$ & $B(\mathrm{~m})$ & $v$ & $k_{\mathrm{s}}(\mathrm{m} / \mathrm{d})$ & $k_{r a}(\mathrm{~m} / \mathrm{d})$ & $k_{z a}(\mathrm{~m} / \mathrm{d})$ & $k_{x p}(\mathrm{~m} / \mathrm{d})$ & $k_{z p}(\mathrm{~m} / \mathrm{d})$ \\
\hline Cohesive fill & 0.033 & 0.099 & 2.000 & 0.300 & 5.184 & $9.50 E-04$ & $9.50 E-04$ & $8.34 E-03$ & $8.55 E-04$ \\
Dredger-filled silt & 0.033 & 0.099 & 2.000 & 0.400 & 5.184 & $3.46 E-04$ & $3.46 E-04$ & $3.03 E-03$ & $3.11 E-04$ \\
Silty sand & 0.033 & 0.099 & 2.000 & 0.250 & 5.184 & 2.592 & 2.592 & 20.796 \\
\hline
\end{tabular}

TABLE 3: Field soil sample parameter.

\begin{tabular}{|c|c|c|c|c|c|c|c|c|c|c|}
\hline $\begin{array}{l}\text { Soil } \\
\text { classification }\end{array}$ & Constitutive model & $\begin{array}{c}\text { Elastic } \\
\text { modulus } \\
\left(\mathrm{kN} / \mathrm{m}^{2}\right)\end{array}$ & $\begin{array}{l}\text { Poisson's } \\
\text { ratio }\end{array}$ & $\begin{array}{c}\text { Unit } \\
\text { weight } \\
\left(\mathrm{kN} / \mathrm{m}^{3}\right)\end{array}$ & $\begin{array}{c}\text { Natural } \\
\text { void ratio }\end{array}$ & $\begin{array}{l}\text { Cohesion } \\
(\mathrm{kPa})\end{array}$ & $\begin{array}{c}\text { Internal } \\
\text { friction angle } \\
\left({ }^{\circ}\right)\end{array}$ & $\lambda$ & $k$ & $M$ \\
\hline Cohesive fill & $\begin{array}{c}\text { Mohr-Coulomb } \\
\text { model }\end{array}$ & 7000 & 0.3 & 18.10 & 0.72 & 24.50 & 9.30 & - & - & - \\
\hline $\begin{array}{l}\text { Dredger-filled } \\
\text { silt }\end{array}$ & $\begin{array}{c}\text { Modified Cam Clay } \\
\text { model }\end{array}$ & 300 & 0.4 & 16.95 & 1.56 & 4.00 & 2.30 & 0.22 & 0.04 & 0.77 \\
\hline Silty sand & $\begin{array}{c}\text { Mohr-Coulomb } \\
\text { model }\end{array}$ & 15000 & 0.25 & 17.80 & 0.60 & 0.00 & 20.00 & - & - & - \\
\hline
\end{tabular}

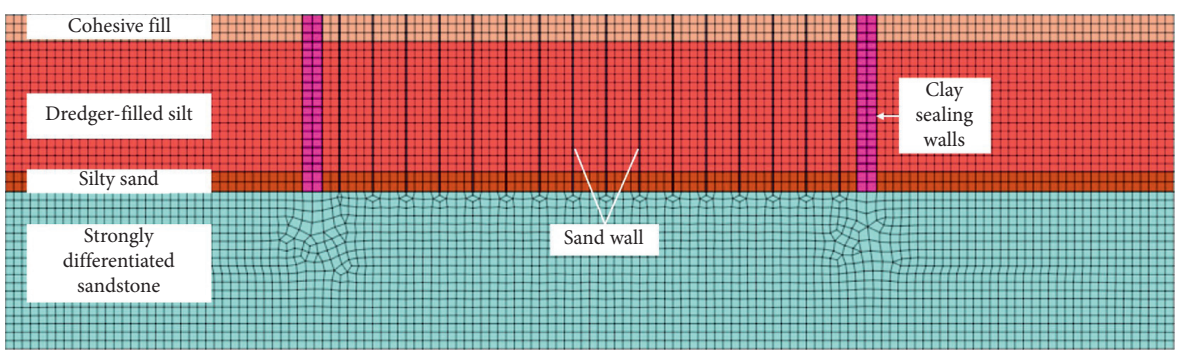

FIGURE 2: Meshing of finite element model of vacuum preloading.

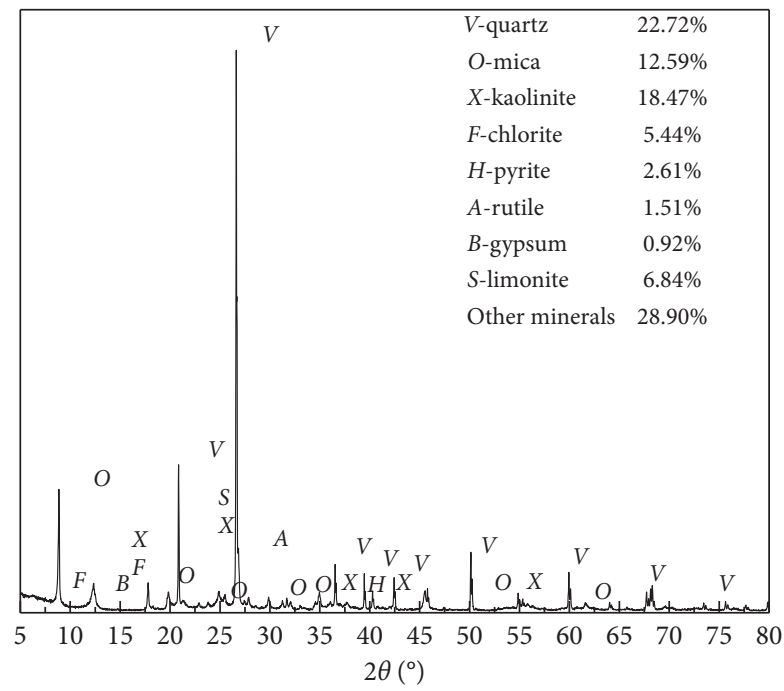

FIGURE 3: Diffraction pattern of mineral composition.

decreases gradually with the increase in depth. Figure 6(a) indicates an apparent inflection point of consolidation pressure between $50 \mathrm{kPa}$ and $100 \mathrm{kPa}$ for dredger-filled silt at a depth of $1 \mathrm{~m}$, unlike for the other two depths. The stress path and cumulative deformation affect the mechanical properties of soil [34]. From the analysis of the scanning electron microscope images (Figure 5), the upper part of the dredging sludge in this area is structural. Meanwhile, the structure of the lower part is unapparent, and the interaction among the dredging sludge particles is more apparent. 


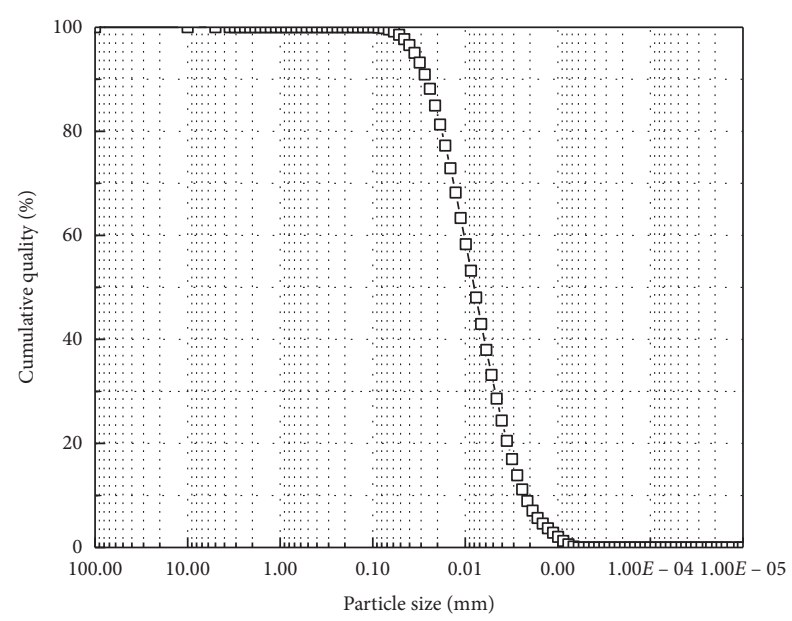

FIgURE 4: Soil grain size distribution curve.

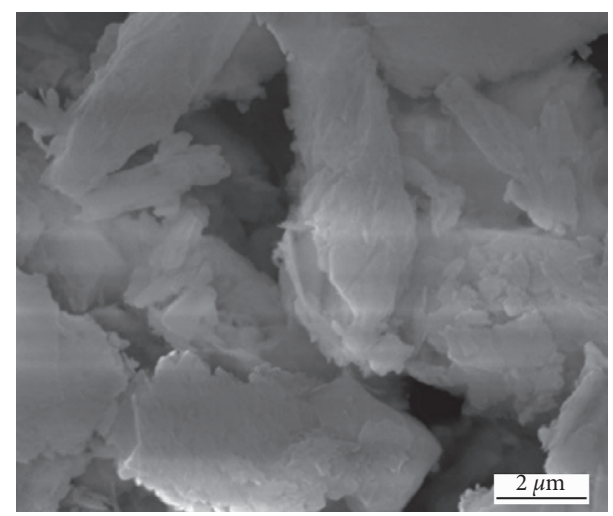

FIGURE 5: Scanning electron micrograph of marine dredger-filled silt.

Figure 6(b) indicates that the axial strain increases gradually with the increase in the consolidation pressure of the dredger-filled silt at the same depth. Under constant consolidation pressure, the axial strain of the dredger-filled silt decreases gradually as the depth increases. In addition, it is illustrated that the dredger-filled silt in this area is in an elastic deformation state when its strain is less than $20 \%$, whereas it is compacted further and enters a dense deformation state when the strain exceeds $20 \%$.

3.3. Numerical Simulation. The vacuum preloading was carried out for 75 days, and the initial water level in the initial stress field of the model was set as $19 \mathrm{~m}$. According to the field monitoring data on pore water pressure, the water level decreased by $6 \mathrm{~m}$ in the field. Therefore, the water level stratified gradually decreased to $13 \mathrm{~m}$ in the finite element model after 75 days of vacuum loading. The result obtained is shown in Figure 7.

Figure 7 shows that the vertical displacement in the middle of the finite element model is concave and that of the surface in the middle is the largest (a settlement of $300 \mathrm{~mm}$ ). The settlement decreases gradually as the depth increases.
The vertical displacement at the bottom is approximately $1 \mathrm{~m}$ above the bottom of the silty sand. The ground surface outside the clay sealing wall is affected by the vacuum preload, and the ground subsides marginally. The larger the distance from the clay sealing wall, the lesser the surface settlement. The area affected by the vacuum preload is $5 \mathrm{~m}$ outside the sealing wall as shown in Figure 7.

In addition, we set up settlement monitoring, pore water pressure monitoring, and vacuum degree monitoring in the center of the field area selected by the finite element model. Therefore, the field and the finite element model have identical stratum conditions as shown in Table 3 and can be compared with each other for analysis. The settlement at different depths along the symmetry axis was selected in the middle of the finite element model of the foundation to analyze the on-site monitoring data on layered settlement including surface settlement. As shown in Figure 8, the surface settlement results of the two conditions are approximately $300 \mathrm{~mm}$, and negligibly different after 75 days. However, the settlement forms are different. On the one hand, the settlement in the finite element model increases linearly and finally stabilizes at $300 \mathrm{~mm}$. On the other hand, the on-site foundation settlement shows a growing curve in the early stage, linear growth in the middle stage, and gradually stabilized in the final stage.

Figure 8 shows that the results and trends of the settlement on site and in the finite element model, at depths of $4 \mathrm{~m}$ and $7 \mathrm{~m}$, are approximately similar. The settlement is stable at approximately $140 \mathrm{~mm}$ at a depth of $4 \mathrm{~m}$, and approximately $50 \mathrm{~mm}$ at a depth of $7 \mathrm{~m}$. Overall, the settlement decreases as the depth increases. However, there is an evident difference in the settlement in the early stage between the site and finite element model. This phenomenon can be explained by the low vacuum sealing effect during the on-site vacuuming process, which results in air leakage (Figure 9).

Owing to the air leakage on site during the 15th-20th day of vacuuming, the settlement of the site at depths of $4 \mathrm{~m}$ and $7 \mathrm{~m}$ shows a short upward adjustment. The settlement at each depth of the site increases linearly when the vacuum is maintained at $85 \mathrm{kPa}$. The rapid rate of surface subsidence in the early stage of the site is because the vacuum source in the shallow layer of the ground causes a relatively sufficient vacuum in the early stage of vacuuming. The water level decreases gradually with the consolidation of the foundation. At present, the vacuum is relatively insufficient, and it is difficult to be satisfied with the deep soil resulting in the decreasing settlement rate of the surface later.

The pore water pressure at the depths of $3 \mathrm{~m}, 6 \mathrm{~m}$, and $9 \mathrm{~m}$ monitored on site and the pore water pressure variation curve at these depths calculated by the finite element method are shown in Figure 10. The figure shows that the trend of pore water pressure at the depths of $6 \mathrm{~m}$ and $9 \mathrm{~m}$ is essentially identical. Meanwhile, the field pore water pressure at the depth of $3 \mathrm{~m}$ is significantly lower than the pore water pressure calculated by the finite element method. This is because, during the vacuuming process, the depth of $3 \mathrm{~m}$ is close to the surface, and the shallow foundation has been drained and consolidated. The pore water pressure measured 


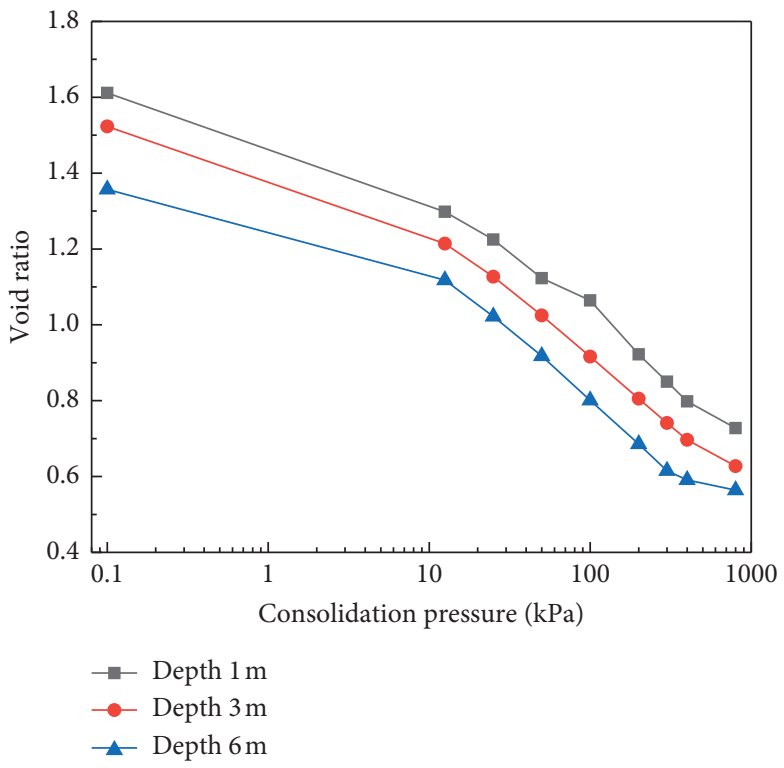

(a)

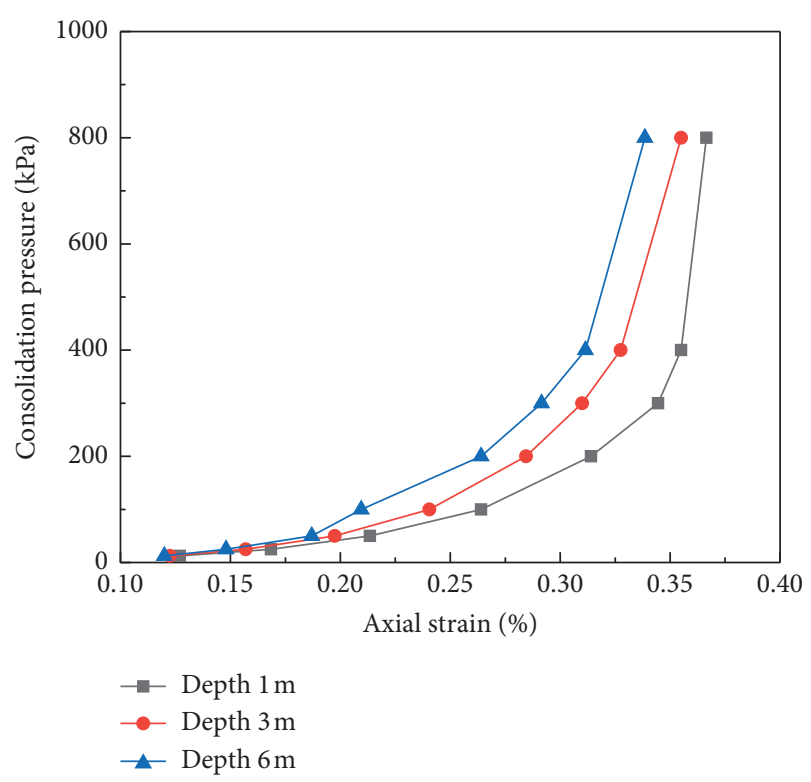

(b)

FiguRE 6: Oedometer test data: (a) relationship between void ratio of dredger-filled silt and variation in consolidation pressure at different depths; (b) relationship between consolidation pressure and axial strain of dredger-filled silt at different depths.

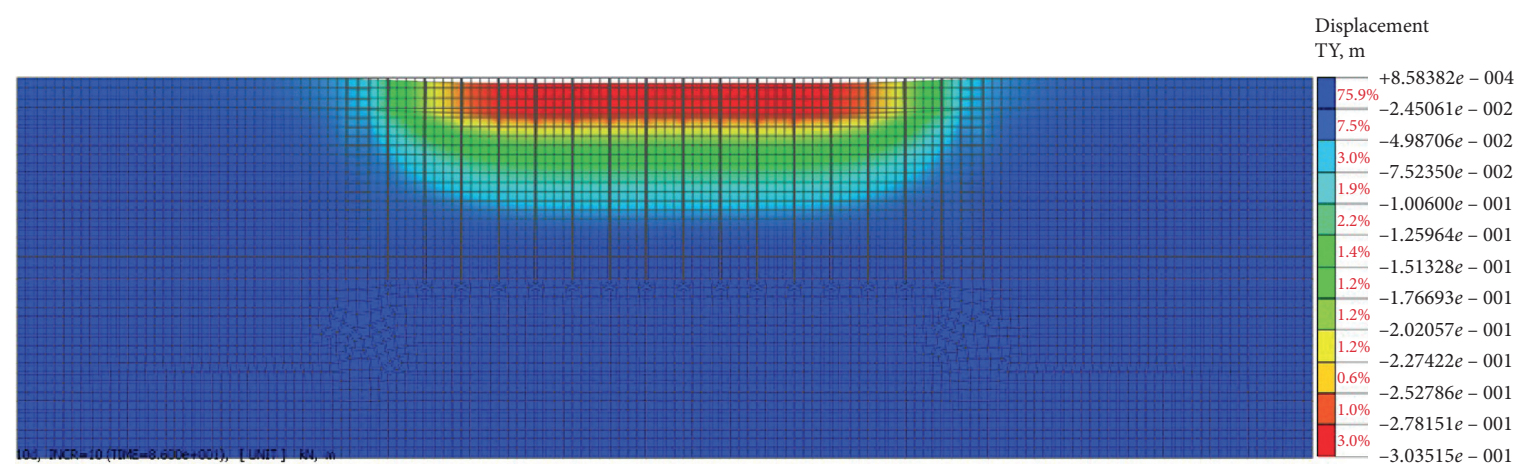

FiguRe 7: Cloud diagram of vacuum preloading settlement.

at this time includes the negative pressure caused by the onsite vacuuming. The pore water pressure at each depth decreases stepwise because layered precipitation was adopted in the finite element calculation model. This demonstrates that layered precipitation can better simulate the on-site vacuum drainage consolidation process.

3.4. Microstructural Evolution. The dredger-filled silt is the sedimentary soil formed by hydraulic dredging using a dredger and mud pump. The depositional process of dredger-filled silt is divided into three stages: silt falling under self-weight stage, self-weight consolidation stage, and sedimentation balance stage [35]. The dredger-filled silt at different depths in different consolidation states is considered for analysis with a scanning electron microscope (SEM), as shown in Figure 11.

The figure indicates that the microstructure of marine dredger-filled silt at different depths varies significantly. This is reflected mainly by two indicators: structural unit and pore unit, i.e., equivalent diameter and abundance. The equivalent diameter refers to the diameter of the equivalent circle whose area is equal to that of the pore unit or structural unit in the soil microstructure. Abundance refers to the ratio of the long axis to the short axis of a pore unit or structural unit. The equivalent diameter and abundance of the pore units and structural units of the dredger-filled silt at different depths are measured according to Figure 11. The results are shown in Table 4.

As the depth of the dredger-filled silt increases, the equivalent diameter of the pores decreases gradually, and the pore abundance increases gradually and shifts away from one. This implies that as the depth of the marine dredgerfilled silt increases, the pores between structural units become increasingly small, whereas the pores tend to be flat. As the depth increases, the equivalent diameter of structural units decreases gradually, and the abundance increases gradually and approaches one. This implies that as the depth 


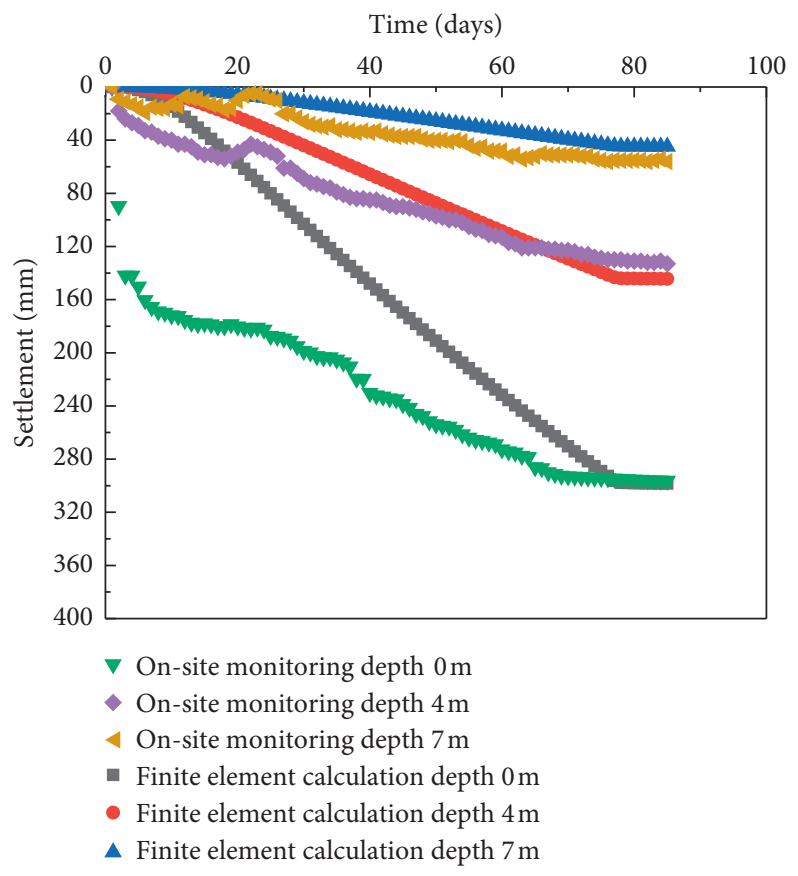

FIGURE 8: Comparison of settlement calculated by finite element and on-site monitoring settlement.

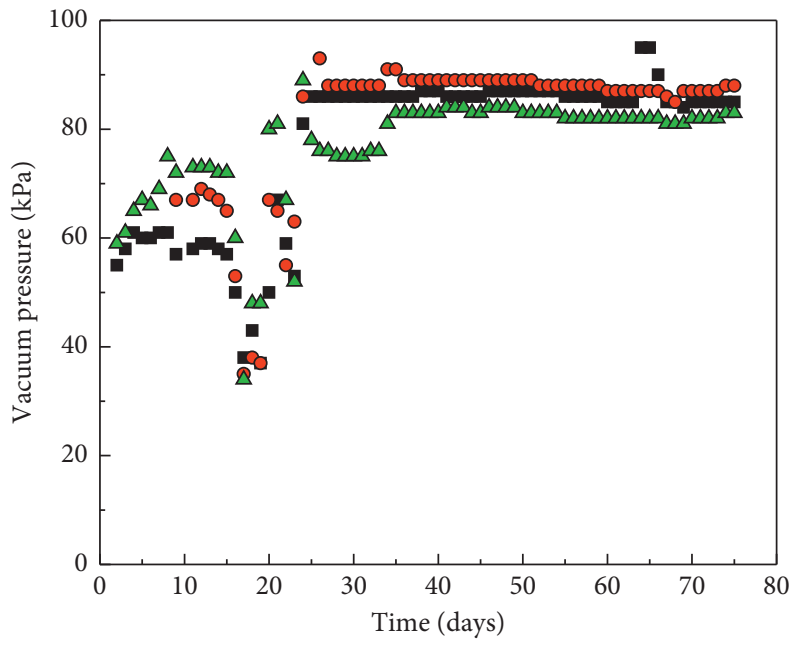

- Vacuum pressure under membrane 1

- Vacuum pressure under membrane 2

$\Delta$ Vacuum pressure under membrane 3

Figure 9: On-site monitoring of relationship between vacuum degree and time.

of the marine dredger-filled silt increases, the soil flocs are compressed and gradually become smaller. Furthermore, the flocs change from long strips to standard circles. In addition,
Figure 11(b) shows that the soil flocs at a depth of $3 \mathrm{~m}$ are bent. This indicates that the squeezing effect between the flocs is becoming increasingly apparent. Simultaneously, as 


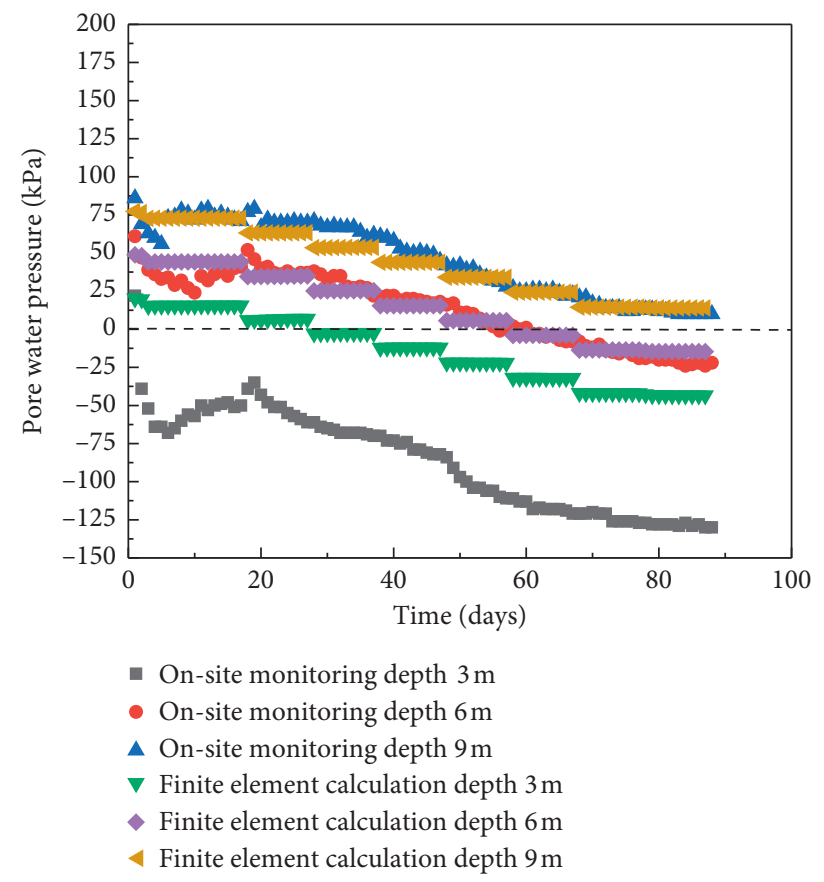

Figure 10: Comparison of field pore water pressure and finite element calculation at different depths.

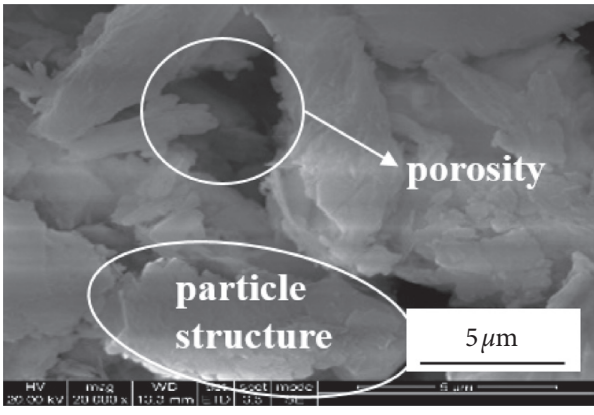

(a)

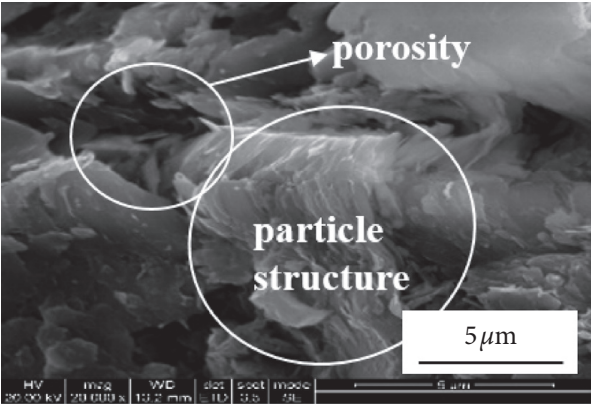

(b)

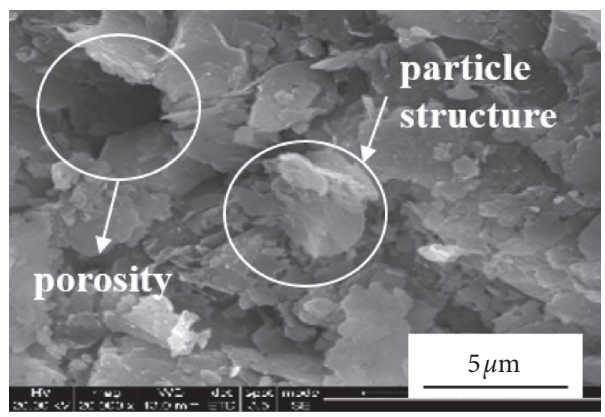

(c)

Figure 11: SEM images from different depths of dredging silt: (a) depth $=1 \mathrm{~m}$; (b) depth $=3 \mathrm{~m}$; (c) depth $=6 \mathrm{~m}$.

Table 4: Equivalent diameter and abundance at different depths of dredger-filled silt unit types.

\begin{tabular}{lcccccc}
\hline Unit type & \multicolumn{3}{c}{ Equivalent diameter } & \multicolumn{3}{c}{ Abundance } \\
Depth $3 \mathrm{~m}$ & Depth $6 \mathrm{~m}$ & Depth $1 \mathrm{~m}$ & Depth 3 m & Depth 6 m \\
\hline Soil porosity & 4.40 & 2.85 & 2.80 & 1.33 & 2.00 \\
Soil structure & 7.82 & 7.25 & 4.63 & 0.36 & 0.84 & 0.93 \\
\hline
\end{tabular}


the pores decrease, the connection between the soil flocs becomes tighter, and the interaction between the particles becomes stronger.

\section{Conclusions}

This study investigated the consolidation characteristics and the micromechanism of dredger-filled silt from the macroand microperspectives, through mineral analysis, pore microstructure analysis, consolidation test, and finite element simulation. The conclusions are as follows:

(1) The mineral analysis of the field dredger-filled silt revealed that the dredger-filled silt in this area is plastic and has a large sand content. The grain size analysis revealed that the dredger-filled silt is composed mainly of powder particles, followed by clay particles.

(2) The oedometer test of the dredger-filled silt showed that its void ratio decreases gradually with the increase in depth. Moreover, the shallow silt is structural, and the deep silt has no apparent structure. The dredger-filled silt is in an elastic deformation state when the axial strain is less than $20 \%$, whereas it enters a compact deformation state when the strain is at least $20 \%$.

(3) The three-dimensional sand well foundation is transformed into a two-dimensional plane strain sand wall foundation for finite element calculation. The results show that the settlement law and pore water pressure dissipation rate are essentially consistent with the on-site monitoring results. Therefore, the use of layered precipitation and node heads in the finite element calculation to simulate vacuum drainage consolidation is in line with the reality.

(4) The analysis and comparison of the scanning electron micrographs of the dredger-filled silt at different depths show that as the depth increases, the equivalent diameter of the structural unit and pore unit of the marine dredger-filled silt decreases, whereas the abundance increases. However, the abundance of structural units approaches one, and the pore unit keeps shifting away from one.

\section{Data Availability}

The data used to support the findings of this study are available from the corresponding author upon request.

\section{Conflicts of Interest}

The authors declare that they have no conflicts of interest.

\section{Acknowledgments}

The authors are grateful to the National Natural Science Foundation of China (Projects no. 42072318, 41972282, and 41807253) and the Pre-Consolidation Characteristics of Marine Muddy Dredger Fill Project (Project no. 43010100) for the financial support. They are also grateful to the Research Fund Program of the Key Laboratory of Geotechnical and Underground Engineering (Tongji University), Ministry of Education (Project no. KLE-TJGE-B1803).

\section{References}

[1] M. Martín-Antón, V. Negro, J. M. Campo del et al., "Review of coastal land reclamation situation in the world," Journal of Coastal Research, vol. 75, no. 1, pp. 667-671, 2016.

[2] Q. Yu, X. Yan, Q. Wang et al., "X-ray computed tomographybased evaluation of the physical properties and compressibility of soil in a reclamation area," Geoderma, vol. 375, Article ID 114524, 2020.

[3] Y. He, M. M. Wang, D. Y. Wu, K. N. Zhang, and W. M. Ye, "Effects of chemical solutions on the hydromechanical behavior of a laterite/bentonite mixture used as an engineered barrier," Bulletin of Engineering Geology and the Environment, vol. 80, no. 3, pp. 1-12, 2020.

[4] Y. He, W. M. Ye, Y. G. Chen, K. N. Zhang, and D. Y. Wu, "Effects of $\mathrm{NaCl}$ solution on the swelling and shrinkage behavior of compacted bentonite under one-dimensional conditions," Bulletin of Engineering Geology and the Environment, vol. 79, no. 3, pp. 399-410, 2019.

[5] J. J. Liu, H. Y. Lei, G. Zheng et al., "Laboratory model study of newly deposited dredger fills using improved multiple-vacuum preloading technique," Journal of Rock Mechanics and Geotechnical Engineering, vol. 9, no. 5, pp. 924-935, 2017.

[6] L. L. Zeng, Z. S. Hong, and Y. J. Cui, “Time-dependent compression behaviour of dredged clays at high water contents in China," Applied Clay Science, vol. 123, pp. 320-328, 2016.

[7] L. L. Zeng, Z. S. Hong, and Y. F. Gao, "Practical estimation of compression behaviour of dredged clays with three physical parameters," Engineering Geology, vol. 217, pp. 102-109, 2017.

[8] J. Wang, Y. Cai, H. Fu et al., "Experimental study on a dredged fill ground improved by a two-stage vacuum preloading method," Soils and Foundations, vol. 58, no. 3, pp. 766-775, 2018.

[9] R. A. Barron, "Consolidation of fine-grained soils by drain wells by drain wells," Transactions of the American Society of Civil Engineers, vol. 113, no. 1, pp. 718-742, 1948.

[10] H. D. Cheng and J. A. Liggett, "Boundary integral equation method for linear porous-elasticity with applications to soil consolidation," International Journal Numerical Methods in Engineering, vol. 20, no. 2, pp. 255-278, 2010.

[11] C. Rujikiatkamjorn and B. Indraratna, "Design procedure for vertical drains considering a linear variation of lateral permeability within the smear zone," Canadian Geotechnical Journal, vol. 46, no. 3, pp. 270-280, 2009.

[12] H. Abuel-naga and A. Bouazza, "Equivalent diameter of a prefabricated vertical drain," Geotextiles and Geomembranes, vol. 27, no. 3, pp. 227-231, 2009.

[13] H. M. Abuel-naga, B. Abdelmalek, and D. T. Bergado, "Numerical assessment of equivalent diameter equations for prefabricated vertical drains," Canadian Geotechnical Journal, vol. 49, no. 12, pp. 1427-1433, 2012.

[14] L. Q. Sun, S. W. Yan, and W. Li, "Research on finite element analysis method of vacuum-surcharge combined preloading to strengthen dredger fill foundation," Chinese Journal of Geotechnical Engineering, vol. 32, no. 4, pp. 592-599, 2010.

[15] C. Huang, Y. Deng, and F. Chen, "Consolidation theory for prefabricated vertical drains with elliptic cylindrical 
assumption," Computers and Geotechnics, vol. 77, pp. 156166, 2016.

[16] E. Cascone and G. Biondi, "A case study on soil settlements induced by preloading and vertical drains," Geotextiles and Geomembranes, vol. 38, pp. 51-67, 2013.

[17] J. Wu, Y. Xuan, Y. Deng et al., "Combined vacuum and surcharge preloading method to improve lianyungang soft marine clay for embankment widening project: a case," Geotextiles and Geomembranes, vol. 49, 2020.

[18] J. Liu, H. Lei, G. Zheng et al., "Improved synchronous and alternate vacuum preloading method for newly dredged fills: laboratory model study," International Journal of Geomechanics, vol. 18, no. 8, Article ID 04018086, 2018.

[19] K. W. Liu and R. K. Rowe, "Numerical modelling of prefabricated vertical drains and surcharge on reinforced floating column-supported embankment behaviour," Geotextiles and Geomembranes, vol. 43, no. 6, pp. 493-505, 2015.

[20] G. Ye, Q. Zhang, Z. Zhang et al., "Centrifugal modeling of a composite foundation combined with soil-cement columns and prefabricated vertical drains," Soils and Foundations, vol. 55, no. 5, pp. 1259-1269, 2015.

[21] A. J. Manning, J. V. Baugh, J. R. Spearman et al., “The settling dynamics of flocculating mud-sand mixtures: part 1-empirical algorithm development," Ocean Dynamics, vol. 61, no. 2-3, pp. 311-350, 2011.

[22] J. R. Spearman, A. J. Manning, and R. J. S. Whitehouse, "The settling dynamics of flocculating mud and sand mixtures: part 2-numerical modelling," Ocean Dynamics, vol. 61, no. 2-3, pp. 351-370, 2011.

[23] Z. Q. Zhang, Q. Wang, Z. Zhang et al., "Changes in structure and physical properties of dredger fill during consolidation," Journal of Tianjin University, vol. 47, no. 6, pp. 504-511, 2014.

[24] Y. Liu, S. F. Xiao, and Q. Wang, "Laboratory simulation test of dredger fill," Rock and Soil Mechanics, vol. 4, pp. 521-528, 2004.

[25] I. Gratchev and I. Towhata, "Compressibility of natural soils subjected to long-term acidic contamination," Environmental Earth Sciences, vol. 64, no. 1, pp. 193-200, 2011.

[26] Y. He, B.-B. Li, K.-N. Zhang, Y.-G. Chen, and W.-M. Ye, "Experimental and numerical study on heavy metal contaminant migration and retention behavior of engineered barrier in tailings pond," Environmental Pollution, vol. 252, pp. 1010-1018, 2019b.

[27] A. Kaya, O. A. Hakan, and Y. Yukselen-Aksoy, "Settling of kaolinite in different aqueous environment," Marine Georesources \& Geotechnology, vol. 24, no. 3, pp. 203-218, 2006.

[28] S. Erouleil and P. Vaughan, "The general and congruent effects of structure in natural soil and weak rock," Geotechnical and Geoenvironmental Engineering, ASCE, vol. 3, no. 40, pp. 467-488, 1990.

[29] A. W. Yang, Y. X. Zheng, and M. Xiao, "Experimental study on long-term deformation characteristics of artificially prepared structural soft clay," Hydrogeology \& Engineering Geology, vol. 46, no. 2, pp. 133-140, 2019.

[30] C. Zhang, J. Z. Li, and Y. He, "Impact of the loading rate on the unsaturated mechanical behavior of compacted red clay used as an engineered barrier," Environmental Earth Sciences, vol. 135, 2021.

[31] Y. X. Cheng, D. Du, and Z. L. Li, "Microstructure effect of shear failure of structural dredger fill," Hydrogeology \& Engineering Geology, vol. 35, no. 1, pp. 32-35, 2008.

[32] C. Zhang, J. Z. Li, and Y. He, "Application of optimized grey discrete Verhulst-BP neural network model in settlement prediction of foundation pit," Environmental Earth Sciences, vol. 78, no. 11, p. 441, 2019.

[33] J. Saowapakpiboon, D. T. Bergado, P. Voottipruex et al., "PVD improvement combined with surcharge and vacuum preloading including simulations," Geotextiles and Geomembranes, vol. 29, no. 1, pp. 74-82, 2011.

[34] A. W. Yang, M. S. Zhao, and Q. Liu, "Considering the influence of stress path and cumulative deformation on the mechanical properties of dredger fill," Chinese Journal of Underground Space and Engineering, vol. 14, no. 5, pp. 1284-1291, 2018.

[35] X. Xiong, J. Peng, K. Zhang et al., "Research on settlement characteristics of wenzhou dredger fill," Journal of Water Resources and Architectural Engineering, vol. 10, no. 6, pp. 78-82, 2012. 